\title{
A Novel Co-planar Waveguide-fed Direct Current Wide Band Printed Dipole Antenna
}

\author{
Yanghua Gao*, Hailiang Lu \\ Information Center, China Tobacco Zhejiang Industrial Co., Ltd, Hangzhou 310008, China
}

Corresponding Author Email: yhgao@zju.edu.cn

https://doi.org/10.18280/ts.360308

Received: 28 February 2019

Accepted: 7 May 2019

\section{Keywords: \\ dipole antenna, coplanar waveguide $(C P W)$, base station, radio frequency identification (RFID)}

\begin{abstract}
In this paper, a co-planar waveguide (CPW)-fed direct current (DC) wide band printed dipole antenna is developed for base stations or radio frequency identification (RFID) applications that work in the ultrahigh frequency (UHF) band. Multiple symmetric loops were designed for the antenna to extend the frequency range of operations. Meanwhile, the structural parameters were analyzed and optimized in turns. The simulation results demonstrate that the proposed antenna can operate at a frequency band from 650 to $1150 \mathrm{MHz}$, with a return loss better than $10 \mathrm{~dB}$. In addition, the radiation patterns were observed as a typical dipole-type pattern. The gain of the antenna ranged from 2.3 to $2.9 \mathrm{dBi}$. Therefore, the proposed antenna is very suitable for various applications requiring high-performance receiving and transmitting.
\end{abstract}

\section{INTRODUCTION}

To improve the receiving performance, base stations or radio frequency identification (RFID) applications can adopt a dipole antenna with broad bandwidth, stable performance and omni-direction [1-3]. For example, Liu et al. [4] designs several wide band antennas that operate at the ultrahigh frequency (UHF) band $(470 \sim 860 \mathrm{MHz})$ and applies them in wireless local area network (WLANs) with the frequencies of 2.4 or $5.8 \mathrm{GHz}$.

Planar antennas can be realized by either microstrip-line fed [5-7] or co-planar waveguide (CPW)-fed [8-10]. With no soldering point and a single metallic layer, the CPW-fed is easy to fabricate and simple in structure. The previous research has shown that CPW-fed printed antennas can achieve satisfactory impedance matching over a wide frequency range, and maintain nearly omni-directional radiation [11-13].

This paper develops a CPW-fed direct current (DC) wide band printed dipole antenna with multiple symmetric loops for base stations or RFID applications that work in the UHF band. Firstly, the antenna structure was optimized under the CPWfed mechanism to yield the maximum bandwidth. The wide band features of the CPW-fed dipole antenna were achieved by the additional resonant mode adjacent to fundamental resonant mode (0.5-wavelength) of the antenna, which is triggered by the straight feed gap. Next, a novel balun DC ground structure was developed for the dipole antenna to generate more resonant modes. Since each loop corresponds to a specific frequency response, the multiple loops can produce an integrated frequency response. Thus, the frequency responses of multiple loops were coupled to stretch the frequency range.

The remainder of this paper is organized as follows: Section 2 describes the structure of the CPW-fed antenna; Section 3 verifies the effectiveness of the antenna through experimental simulation; Section 4 concludes the design of the antenna.

\section{STRUCTURE OF THE PROPOSED ANTENNA}

As shown in Figure 1, the CPW-fed direct current (DC) wide band printed dipole antenna consists of two parts, namely, a pair of symmetric dipoles and the balun DC ground structure. With a rectangular radiation area $(178 \mathrm{~mm} \times 65 \mathrm{~mm})$, the dipoles were printed on a $1.6 \mathrm{~mm}$ FR4 dielectric substrate (dielectric constant: 4.4 ; loss tangent: 0.018 ).

The radiating portion of the CPW-fed dipole antenna was disposed on the same layer of the FR4 substrate. The CPWfed feeding structure and the balun DC ground structure were arranged symmetrically across the middle of the board. As shown in Figure 1(a), the dipoles have multiple symmetric loops, which are made up of the radiated strip lines.

The dimensions in Figure 1 are the preferred design parameters. The $178 \mathrm{~mm}$-long dipole antenna can produce a fundamental resonant mode (0.5-wavelength) centered at about $650 \mathrm{MHz}$. Therefore, the frequency range of the dipole antenna is up to $700 \mathrm{MHz}$ in the UHF band. To extend the frequency up to $1,000 \mathrm{MHz}$, an additional resonant mode was activated by a straight feed gap. In the dipole antenna, the resonant frequencies of multiple loops were coupled to enhance the impedance matching in the whole UHF band.

The radiated structure of the $\mathrm{CPW}$-fed dipole antenna was connected to the feed port through the feeding cable. The generalized transmission-line theory was adopted to determine the multiple resonance modes of the structure. The radiated structure and the symmetric loops enable the dipole antenna to adjust the impedance and electrical length of each element, thus achieving the substantial control of different resonance modes. 


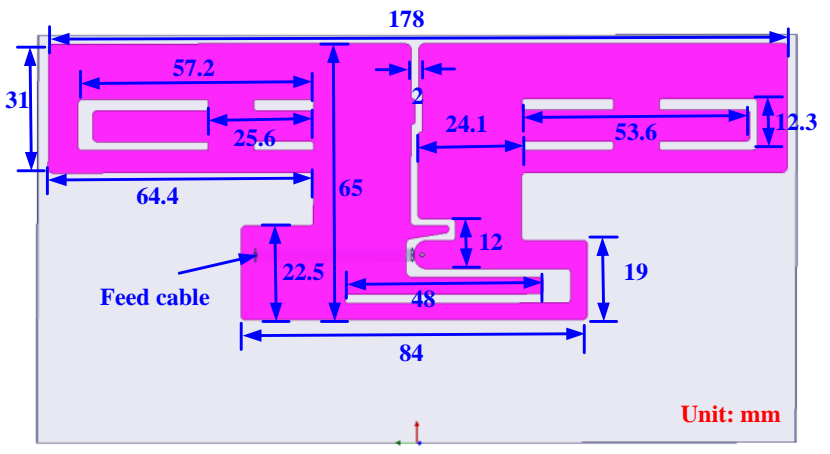

(a) Dimensions of radiating element

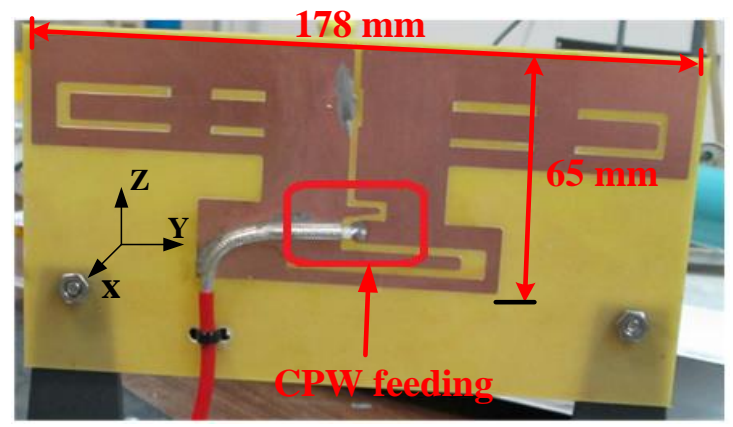

(b) A photo of prototype antenna

Figure 1. Structure of the CPW-fed direct current (DC) wide band printed dipole antenna

\section{EXPERIMENTAL VERIFICATION AND RESULTS ANALYSIS}

The return losses of the proposed dipole antenna were measured in an anechoic chamber with AgilentE5063A network analyzer, and also simulated with ANSYS HFSS, a 3D electromagnetic (EM) simulation software for designing and simulating high-frequency electronic products [14-16]. The measured and simulated return losses are compared in
Figure 2. Obviously, the two results agree well with each other. Under the Voltage Standing Wave Ratio (VSWR)of 2.0:1 ($10 \mathrm{~dB}$ return loss), the bandwidth was measured as $500 \mathrm{MHz}$ $(650 \sim 1150 \mathrm{MHz})$, which covers the operations of LTE/CDMA/GSM800/900.

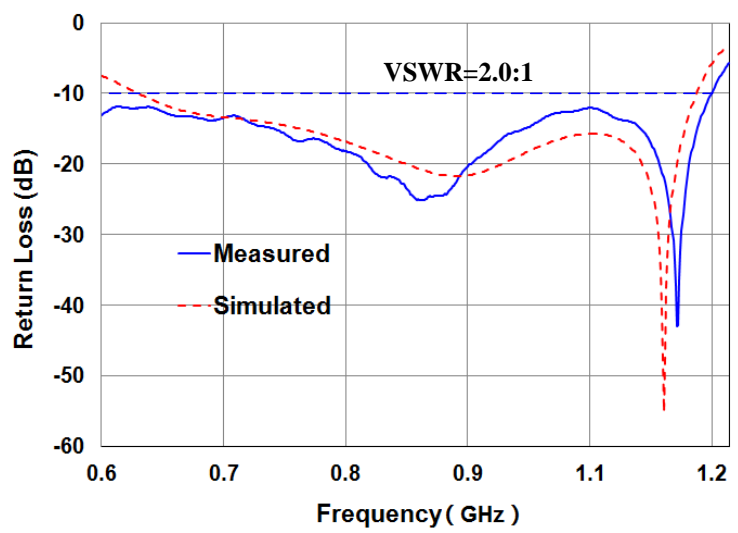

Figure 2. The measured and simulated return losses of the proposed dipole antenna

Next, the 2D radiation pattern of the prototype antenna was observed at 698,853 and $960 \mathrm{MHz}$ in the anechoic chamber with far-field system, while the $3 \mathrm{D}$ radiation pattern of the antenna was simulated at the same frequencies. The measured and resulted results are displayed in Figures 3 and 4, respectively. It can be seen that the observed radiation patterns were dipole-like, and the observed radiation patterns for frequencies over the entire wide band $(650 \sim 1,150 \mathrm{MHz})$ were basically consistent with the simulated results. These pattern features are similar to those of conventional dipole-like antenna.

The observed peak gain and radiation efficiency of our antenna are suitable for practical application. In the low band at $800 \mathrm{MHz}$, the antenna's gain varied from about 2.3 to $2.9 \mathrm{dBi}$, and its radiation efficiency remained above $75 \%$ over the entire wide band.

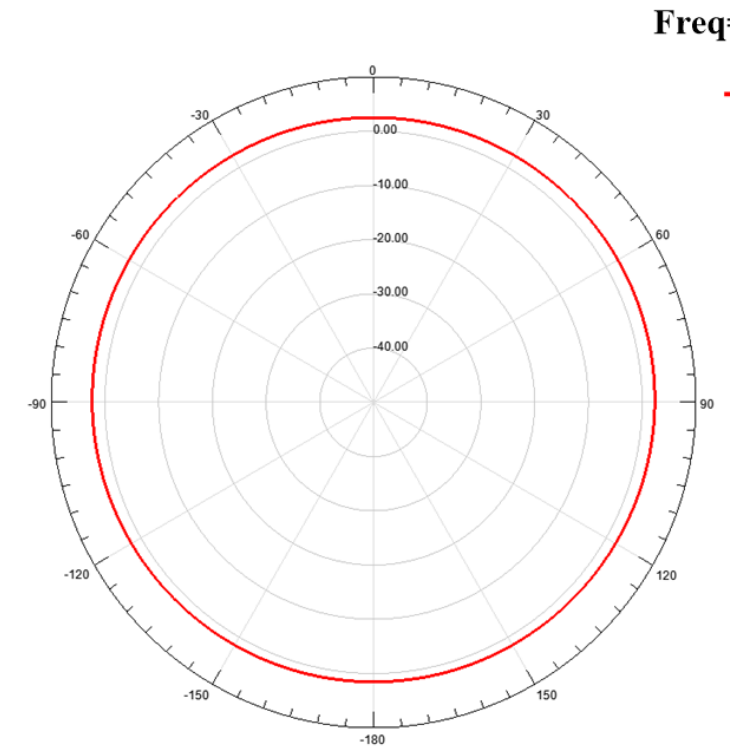

X-Z plane（H-plane）

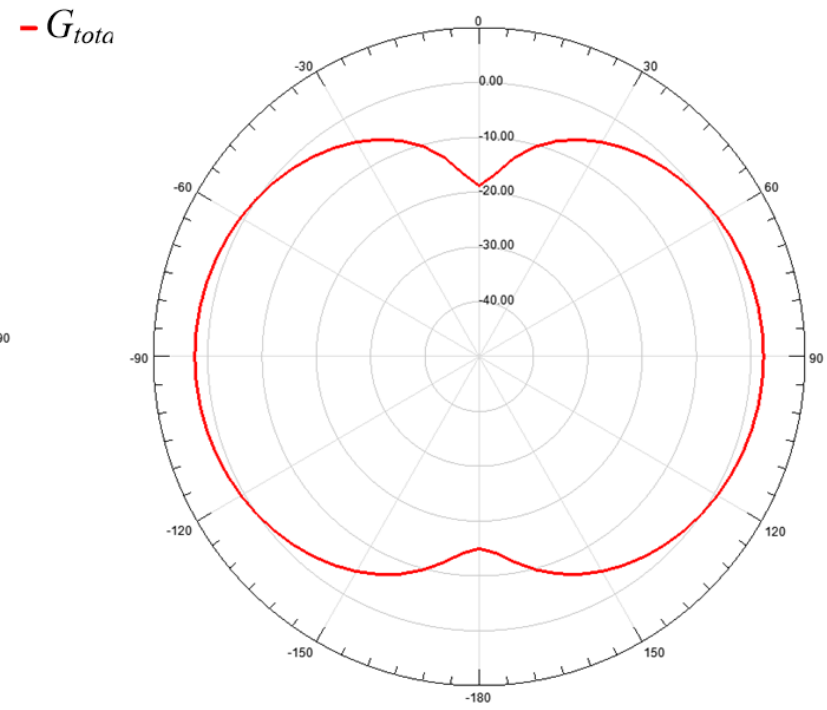

Y-Z plane（E-plane）

(a) $698 \mathrm{MHz}$ 


\section{Freq $=853 \mathrm{MHz}$}

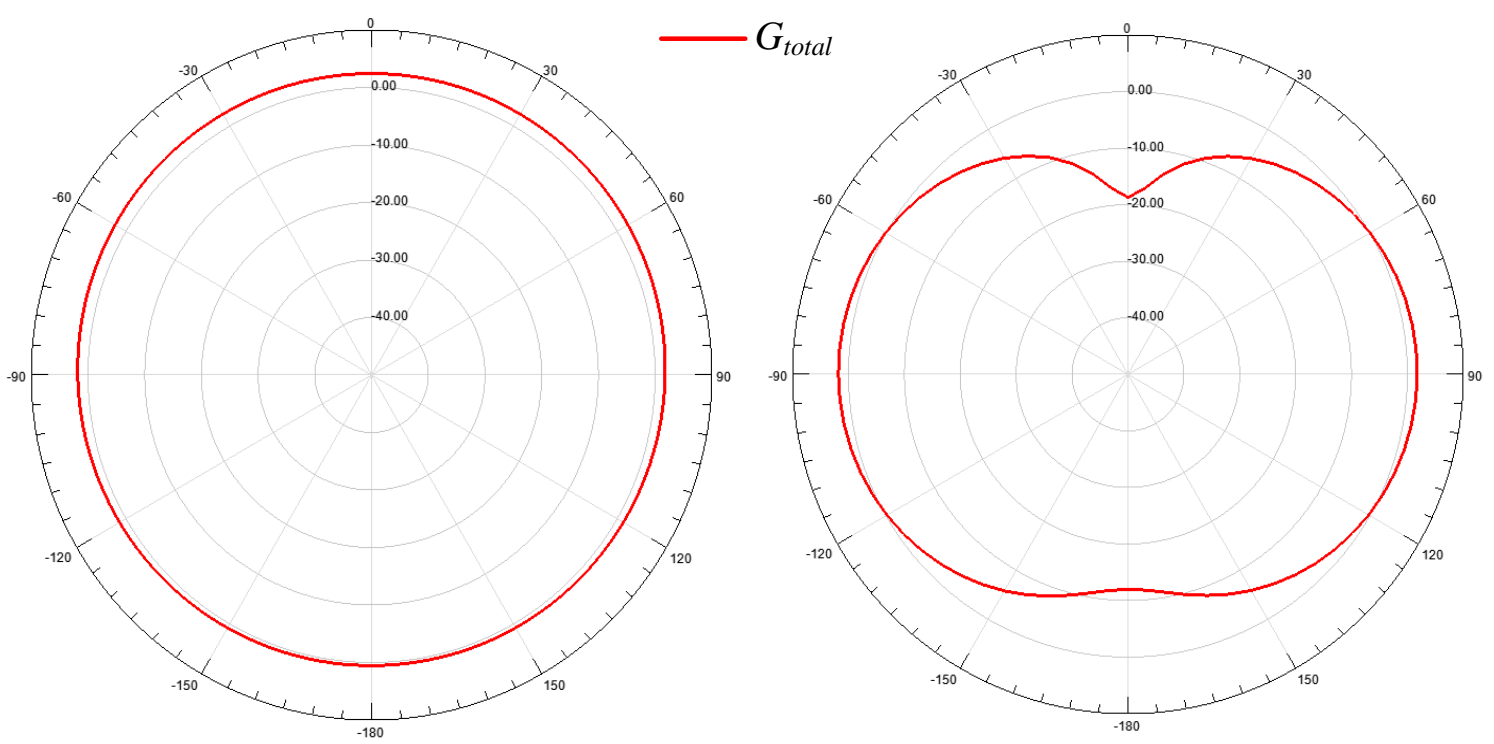

X-Z plane（H-plane）

Y-Z plane（E-plane）

(b) $853 \mathrm{MHz}$

Freq $=960 \mathrm{MHz}$

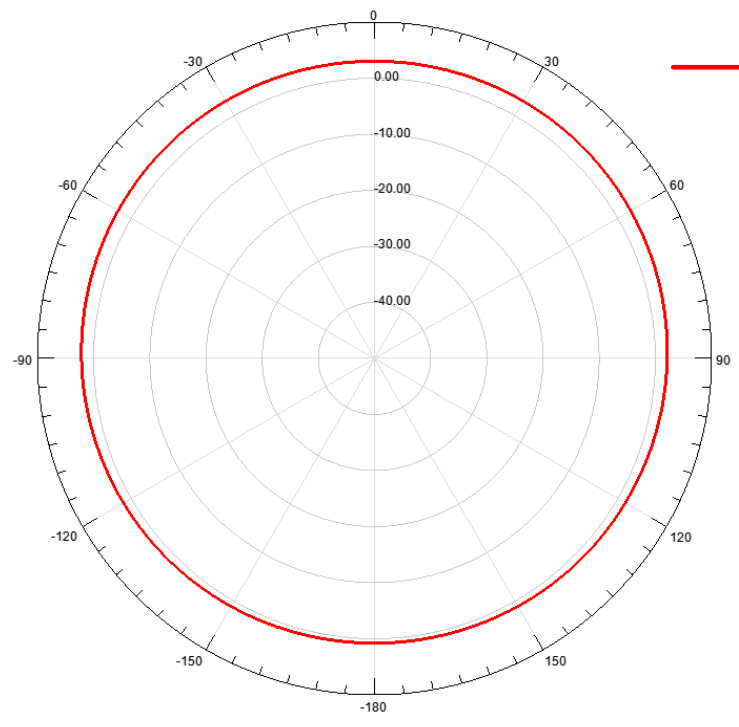

X-Z plane（H-plane )

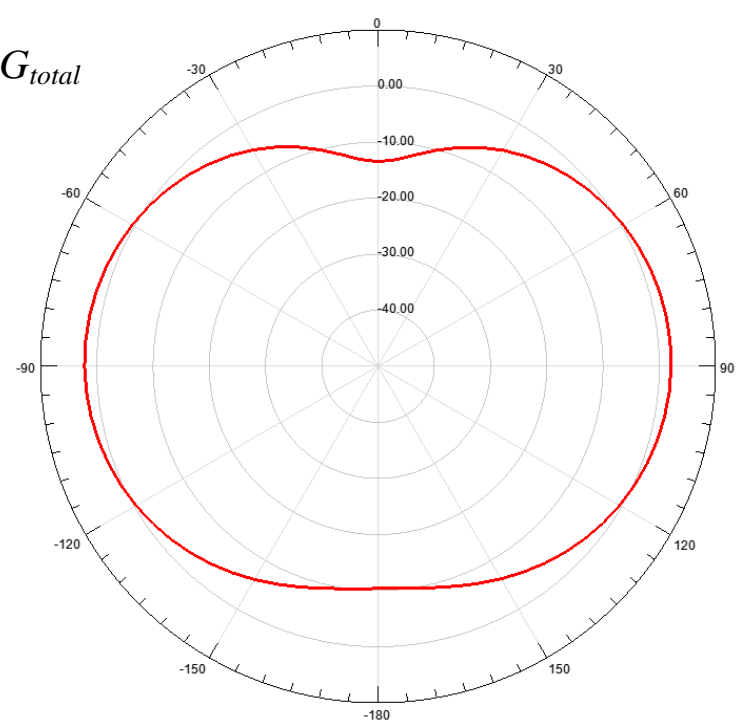

Y-Z plane（E-plane）

(c) $960 \mathrm{MHz}$

Figure 3. Measured 2D radiation patterns

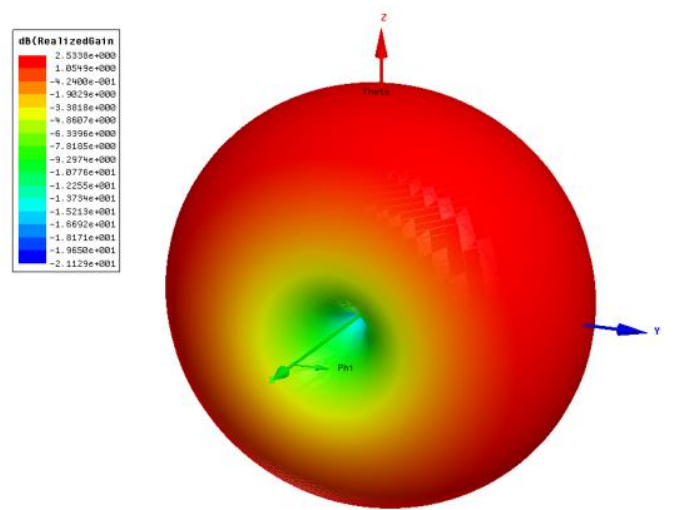

(a) $698 \mathrm{MHz}$

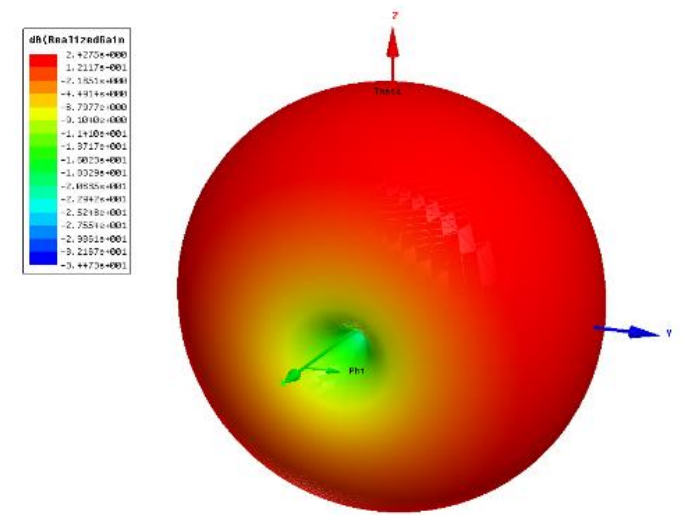

(b) $853 \mathrm{MHz}$ 


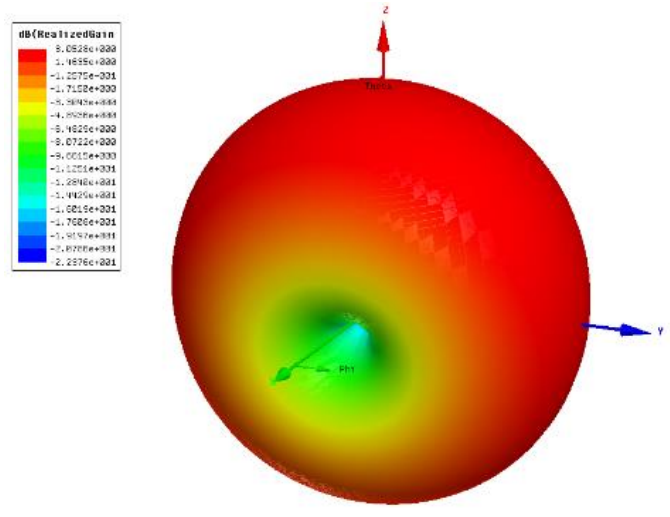

(c) $960 \mathrm{MHz}$

Figure 4. Simulated 3D radiation patterns
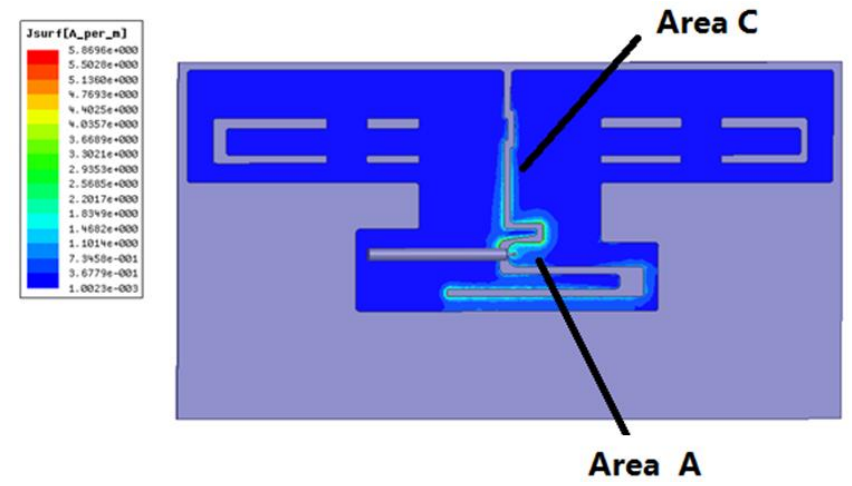

(a) $698 \mathrm{MHz}$
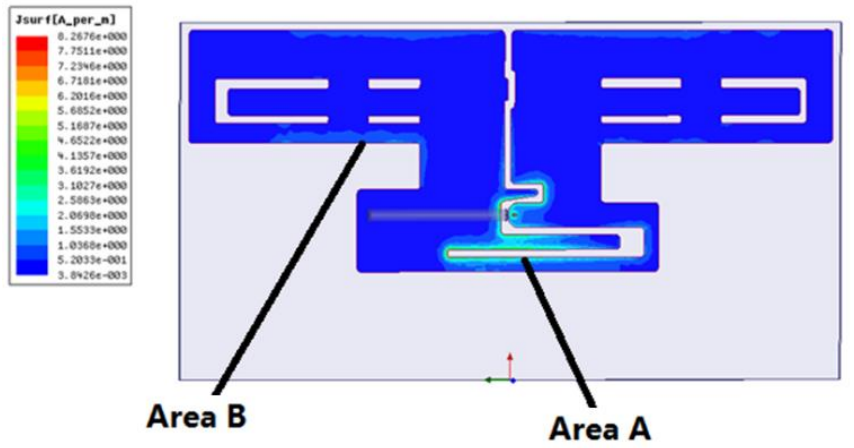

(b) $853 \mathrm{MHz}$
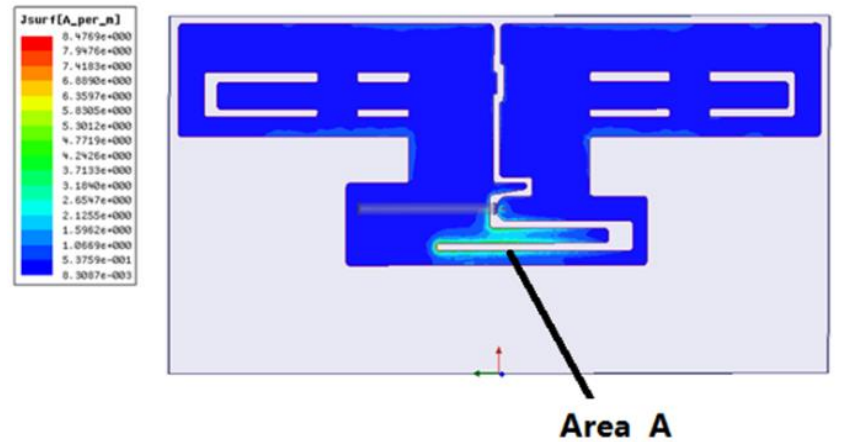

(c) $960 \mathrm{MHz}$

Figure 5. Simulated current distributions

To reflect the resonant mode of our antenna, the surface current distributions were simulated at 698,853 and $960 \mathrm{MHz}$. The results in Figure 5 show that, at $698 \mathrm{MHz}$, the surface currents on areas $\mathrm{A}$ and $\mathrm{C}$ were triggered at the same direction as those excited at the fundamental resonant mode $(0.5$ wavelength) in the conventional dipole antenna. At $830 \mathrm{MHz}$, the surface currents of areas A and B, which were excited by the straight feed gap, went rightward and leftward in the regions close to the gap, respectively. This is similar to the surface currents excited in the second resonant mode of the conventional dipole antenna. The wide band effect is attributable to the following facts. Multiple rectangular loops were employed in a topology like concentric circles. The length of each loop had a unique length, corresponding to a resonant frequency. The interacting resonant frequencies from these loops were coupled to achieve the wide band effect.

\section{CONCLUSIONS}

This paper designs a novel CPW-fed DC wide band printed dipole antenna with a symmetric loop dipole structure and a balun DC ground design. The antenna has a simple planar structure, covering an area of only $178 \times 65 \mathrm{~mm}^{2}$. A prototype of the proposed antenna was fabricated and verified through simulations. The results show that this antenna can generate five resonant modes, covering the bands of LTE/CDMA/GSM800/GSM900/GPS/RFID, and prove that the antenna boasts good radiation efficiency and ultra wide band performance, thanks to its symmetric radiation structure and the innovative DC balun feeding structure.

\section{REFERENCES}

[1] Wong, K.L. (2003). Planar antennas for wireless communications.

[2] Jing, X., Du, Z., Gong, K. (2006). A compact multiband planar antenna for mobile handsets. IEEE Antennas and Wireless Propagation Letters, 5(1): 343-345. https://doi.org/10.1109/LAWP.2006.880690

[3] Hsu, C.K., Chung, S.J. (2010). A wideband DVB forked shape monopole antenna with coupling effect for USB dongle application. IEEE Transactions on Antennas and Propagation, 58(9): 3029-3036. https://doi.org/10.1109/tap.2010.2052545

[4] Liu, H.W., Ku, C.H., Yang, C.F. (2010). Novel CPW-fed planar monopole antenna for WIMAX/WLAN applications. IEEE Antennas and Wireless Propagation Letters, 9: 240-243. https://doi.org/10.1109/LAWP.2010.2044860

[5] Liu, W.C., Wu, C.M., Chu, N.C. (2010). A compact CPW-fed slotted patch antenna for dual band operation. IEEE Antennas and Wireless Propagation Letters, 9: 110-113. https://doi.org/10.1109/LAWP.2010.2044135

[6] Tsai, C.Y., Chen, O.T.C. (2010). CPW-fed wideband printed planar dipole antenna for digital TV. 2011 IEEE International Symposium on Antennas and Propagation (APSURSI): https://doi.org/10.1109/APS.2010.5561721

[7] Abdelghafour, H., Abderrahmen, B., Samir, Z., Riyadh, R. (2018). Backstepping control of a doubly-fed induction machine based on fuzzy controller. European Journal of Electrical Engineering, 20(5-6): 645-657. https://doi.org/10.3166/EJEE.20.645-657

[8] Gosal, G., Almajali, E., McNamara, D., Yagoub, M. (2015). Transmitarray antenna design using forward and inverse neural network modeling. IEEE Antennas and Wireless Propagation Letter, 15: 1483-1486. https://doi.org/10.1109/LAWP.2015.2514065

[9] Guney, K., Sarikaya, N. (2007). A hybrid method based 
on combining artificial neural network and fuzzy inference system for simultaneous computation of resonant frequencies of rectangular, circular, and triangular microstrip antennas. IEEE Transactions on Antennas and Propagation, 55(3): 659-668. https://doi.org/10.1109/TAP.2007.891566.

[10] Hutchings, D.A., El-Shenawee, M. (2014). Microwave MEMS antenna sensor characterization and target detection using artificial neural networks. IEEE Sensors Journal, 14(8): 2461-2468 https://doi.org/10.1109/JSEN.2013.2279662.

[11] Mishra, S., Yadav, R.N., Singh, R.P. (2015). Directivity estimations for short dipole antenna arrays using radial basis function neural networks. IEEE Antennas and Wireless Propagation Letters, 14: 1219-1222. https://doi.org/10.1109/LAWP.2015.2399453.

[12] Terlapu, S.K., Raju, G.S.N. (2014). Design of array antenna for symmetrical sum patterns to reduce close-in sidelobes using particle swarm optimization. AMSE Review (Association for the Advancement of Modelling and Simulation Techniques in Enterprises), 87(3): 44-56.

[13] Zaharis, Z.D., Skeberis, C., Xenos, T.D., Lazaridis, P.,
Cosams, J. (2013). Design of a novel antenna array beamformer using neural networks trained by modified adaptive dispersion invasive weed optimization based data. IEEE Transactions on Broadcasting, 59(3): 455-460. https://doi.org/10.1109/TBC.2013.2244793.

[14] Cao, Y., Reitzinger, S., Zhang, Q.J. (2011). Simple and efficient high dimensional parametric modeling for microwave cavity filters using modular neural network. IEEE Microwave and Wireless Components Letters, 21(5): 258-260. https://doi.org/10.1109/LMWC.2011.2127465

[15] Cao, Y., Wang, G., Gunupudi, P., Zhang, Q.J. (2013). Parametric modeling of microwave passive components using combined neural networks and transfer functions in the time and frequency. International Journal of RF and Microwave Computer-Aided Engineering, 23(1): 20-33. https://doi.org/10.1002/mmce.20630

[16] Qaddoumi, N., El-Hag, A., Saker, Y. (2014). Outdoor insulators testing using artificial neural network-based near-field microwave technique. IEEE Transactions on Instrumentation and Measurement, 63(2): 260-266. https://doi.org/10.1109/TIM.2013.2280486 